\title{
CURRENT COMMENT
}

\section{BASIC BIOLOGY AND CLINICAL APPLICATION OF SPECIFIC CYCLOOXYGENASE-2 INHIBITORS}

\author{
LESLIE J. CROFFORD, PETER E. LIPSKY, PETER BROOKS, STEVEN B. ABRAMSON, \\ LEE S. SIMON, and LEO B. A. VAN DE PUTTE
}

The year 1999 marked the 100th anniversary of the development of aspirin as a pharmaceutical compound used for the treatment of rheumatic diseases. On this anniversary, new drugs developed as a result of advances in the understanding of prostanoid biosynthetic pathways have become available for clinical use. These drugs were specifically designed to inhibit the cyclooxygenase (COX) activity of the inducible isoform of prostaglandin $\mathrm{H}(\mathrm{PGH})$ synthase, or COX-2. The rationale for the intensive drug development effort was the hypothesis that specific inhibition of COX-2 would have equal efficacy to, but significantly fewer gastrointestinal (GI) side effects than the nonsteroidal antiinflammatory drugs (NSAIDs) that nonspecifically inhibit the COX enzymes. Understanding of COX-2 biology provides a rationale for the use of specific COX-2 inhibitors in patients with rheumatic diseases, as well as cautions related to the physiologic functions of COX-2. Data from clinical trials provide support for the COX-2 hypothesis, though data collected after widespread use of the specific COX-2 inhibitors will be needed in order for a full understanding of these new compounds to be achieved.

Leslie J. Crofford, MD: University of Michigan, Ann Arbor; Peter E. Lipsky, MD: University of Texas Southwestern Medical Center, Dallas; Peter Brooks, MD: University of Queensland, Royal Brisbane Hospital, Herston, Australia; Steven B. Abramson, MD: New York University School of Medicine, New York, New York; Lee S. Simon, MD: Harvard Medical School, Boston, Massachusetts; Leo B. A. van de Putte, MD, PhD: University Hospital Nijmegen, Nijmegen, The Netherlands.

With the exception of Dr. van de Putte, each author is either on the advisory board of, a member of a speakers bureau of, a consultant to, or has received research or educational grants from multiple pharmaceutical companies, including G. D. Searle \& Co. and Merck \& Co.

Address reprint requests to Leslie J. Crofford, MD, University of Michigan, 5510E MSRB I, 1150 West Medical Center Drive, Ann Arbor, MI 48109-0680.

Submitted for publication May 14, 1999; accepted in revised form August 13, 1999.

\section{Background}

The antiinflammatory, analgesic, and antipyretic actions of aspirin became well known during the years after its introduction. More recently, the beneficial effects of the antithrombotic actions of aspirin in atherosclerotic disease have been recognized (1). There is strong epidemiologic evidence in support of a role for aspirin as a chemopreventative agent for colon cancer (2). In addition, there is evidence that the progression of Alzheimer's disease may be diminished by aspirin ingestion (2).

The NSAIDs, a group of chemically diverse compounds that share the main therapeutic benefits of aspirin, have also been found to share the most typical side effects of aspirin, i.e., gastric upset, ulceration, and GI bleeding. The common mode of action of these compounds was described in 1971 by Sir John Vane, who recognized that aspirin and NSAIDs inhibit production of PGs (3). He proposed that the therapeutic effects and the main side effects of these compounds result from blocking formation of PGs.

The enzymes involved in the biosynthesis of prostaglandins include the phospholipases that release arachidonic acid from phospholipid membranes, particularly phospholipase $\mathrm{A}_{2}\left(\mathrm{PLA}_{2}\right)$. Arachidonate is metabolized to PG by the bifunctional enzyme cyclooxygenase (COX or PGH synthase), after which stable PGs are formed by a group of synthases. In general, the particular PG produced by a given cell type is determined by the PG synthase present in that cell (4). The principal mechanism of action for aspirin and NSAIDs is inhibition of the enzymatic activity of COX.

Until 1990, it was thought that the rate-limiting step in prostanoid biosynthesis was the availability of arachidonic acid substrate. However, Masferrer et al, in the laboratory of Dr. Philip Needleman, made the observation that $\mathrm{COX}$ protein in mice was increased by exposure to bacterial endotoxin and, furthermore, that 
the levels of COX protein were decreased by glucocorticoids (5). It was also shown that levels of COX protein were increased in rats with experimental inflammatory arthritis and in synovial tissues of patients with rheumatoid arthritis (RA) compared with those of patients with osteoarthritis (OA) (6). It was proposed that different pools of COX might be present, and encoded by differentially regulated genes (5). This hypothesis was shown to be correct when a gene product found to be induced by either stimulation of 3T3 mouse fibroblasts with phorbol ester or infection of chick embryo fibroblasts with the oncogene v-src was identified as an isoform of COX, now known as COX-2 $(7,8)$. Masferrer and coworkers further hypothesized that the presence of different COX enzymes could have functional consequences, that is, one isoform could be responsible for the PGs produced in pathologic situations whereas physiologic PGs might be the product of another COX isoform (5). If this is indeed the case, then specific inhibition of COX-2 might provide the therapeutic benefits associated with NSAIDs without the usual side effects.

\section{Biology of COX-2}

Molecular biology. After the gene for COX-2 was cloned and characterized, comparisons with COX-1 could be made. The most striking difference between the COX isoforms was at the level of basal expression and regulation of the messenger RNA (mRNA) (9). The promoter region of COX-1 has the characteristics of a housekeeping gene, a gene that is continuously transcribed and stably expressed, including the absence of TATA and CAAT elements. COX-1 mRNA and protein are expressed in most tissues under basal conditions as a result of these molecular characteristics of the promoter (10) (Figure 1). COX-1 levels are increased as some cell types differentiate (11); however, mRNA and protein levels do not vary greatly in response to external stimuli in differentiated tissues. COX-1 is the only isoform expressed in platelets, and is responsible for production of PGs that maintain the integrity of normal gastric mucosa (12). COX-1 is also available to increase PG production acutely when an abrupt increase in arachidonate substrate occurs $(13,14)$.

The COX-2 gene has the structure typical of highly regulated gene products (9). The promoter region has TATA and CAAT elements as well as binding sites for transcription factors that act to increase gene transcription immediately in response to external stimuli $(9,15)$. In addition, the $3^{\prime}$-untranslated region encodes multiple mRNA instability sequences that are usually

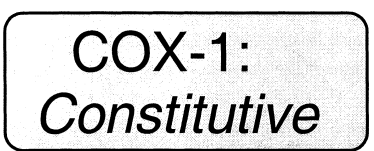

- Homeostatic

- Protection of gastric mucosa

- Platelet activation

- Renal functions

- Macrophage differentiation
COX-2: Regulated

- Pathologic

- Inflammation

- Pain

- Fever

- Dysregulated proliferation

- Tissue Repair

- Physiologic

- Reproduction

- Renal functions

- Other (see text)

- Development

- Kidney
Figure 1. Expression of cyclooxygenase-1 (COX-1) and COX-2. COX-1 expression is constitutive in most tissues. There are a few situations in which COX-1 is modestly increased during cellular differentiation. COX-2 exhibits restricted expression under basal conditions, but can be markedly induced in response to stimulation by cytokines, mitogens/growth factors, hormones, and many other pathologic and physiologic stimuli.

found in genes whose products are rapidly downregulated after induction (16-18). COX-2 has markedly restricted expression under basal conditions, with the highest levels found in the brain, vas deferens, and renal cortex (2). As would be predicted, COX-2 expression is highly induced by a number of cytokines, including interleukin-1 (IL-1), tumor necrosis factor $\alpha$, and other stimuli associated with inflammation and growth $(9,19)$. It has been confirmed that COX-2 expression is inhibited by glucocorticoids in all cells and tissues studied to date (9).

There is considerable variability in the specific transcription factors that mediate increased COX-2 expression depending on the cell type and species under investigation. Several investigators have reported that nuclear factor $\kappa \mathrm{B}(\mathrm{NF}-\kappa \mathrm{B})$ is an important mediator of COX-2 transcription in some human cells, including synovial fibroblast-like cells $(20,21)$, whereas others have reported that NF- $\kappa \mathrm{B}$ has no role in regulating COX-2 expression. Similar cell-type and species variability has been noted for other transcription factors that are likely to play a role in COX-2 regulation, including c/EBP and c-jun (22). In addition to being highly regulated at the transcriptional level, COX-2 expression is regulated posttranscriptionally. IL-1 increases COX-2 mRNA half-life in addition to increasing transcription (18). The 
mechanisms by which glucocorticoids inhibit COX-2 expression have not yet been completely elucidated, and it is likely that transcriptional and posttranscriptional mechanisms are involved (17,23). However, it seems clear that antiinflammatory actions of glucocorticoids are mediated in part through inhibition of prostanoid biosynthesis by inhibiting the expression of COX-2.

Although the synthesis of PGs is regulated acutely by activation of phospholipases and release of arachidonate, the net level of prostanoid production is determined by COX expression (24). Control of COX isoform levels is critical since the enzyme is inactivated during catalysis. Many agents that stimulate arachidonate release, such as cytokines and growth factors, also stimulate transcription of COX-2, and full prostanoid biosynthetic capacity is reached only when COX-2 is induced (24).

Enzymatic activity. Despite differences in the expression and regulation of COX-1 and COX-2, the enzymatic activity of the isoforms is strikingly similar. The crystal structure of both isoforms has been determined, and predictions regarding the interactions of arachidonic acid substrates as well as inhibitors can be made using this information. Both $\mathrm{COX}$ isoforms are localized within the inner leaflet of the phospholipid bilayer of the endoplasmic reticulum and nuclear envelope $(25,26)$. Localization of the COX isoforms may be of importance since COX is one of a cascade of enzymes that participates in $\mathrm{PG}$ production. Of note, cytosolic $\mathrm{PLA}_{2}$, a leading candidate for the principal enzyme generating arachidonic acid in response to external stimuli, translocates to the nuclear envelope upon activation $(27,28)$. The first reaction catalyzed by both $\mathrm{COX}$ isoforms involves the oxidative cyclation of the central 5 carbon atoms of arachidonic acid, leading to the formation of $\mathrm{PGG}_{2}$. This reaction takes place in a hydrophobic channel in the interior of both COX proteins that can be accessed from within the phospholipid membrane. A peroxidation reaction that results in the formation of $\mathrm{PGH}_{2}$ occurs at a separate, but neighboring, catalytic site (4).

Most of the amino acids that form the enzymatic active site of the COX molecules are identical, with the exception of the substitution of valine in COX-2 for isoleucine in COX-1 at position 523. This substitution allows formation of a side pocket in COX-2 that has been shown to be critical in allowing the development of pharmaceutical compounds that specifically inhibit COX-2 (29). The interaction of arachidonate with COX-1 and COX-2 may be different, as evidenced by differing effects of amino acid substitutions for the arginine 120 located at the mouth of the hydrophobic channel in both enzymes. It is likely that an ionic bond with arachidonate is formed by COX-1 while a hydrogen bond is formed by COX-2, suggesting that the hydrophobic cyclooxygenase channel must contribute more significantly to arachidonate binding to COX-2 (30). Overall, COX-2 has a wider and somewhat more flexible interior channel. One consequence of this property of COX-2 is that the interaction of aspirin with COX-2 results in formation of unique fatty acids whose products may have intrinsic antiinflammatory activity (31).

COX-2 in inflammation, pain, and fever. In virtually all models studied, COX-2 expression increases in response to inflammatory stimuli and other types of tissue damage. Since NSAIDs are efficacious in the treatment of arthritis and other forms of acute and chronic inflammation, examination of the relative expression of COX-1 and COX-2 in these types of disorders provides some insight into potential roles for the isoforms and potential therapeutic benefits of specific COX-2 inhibition.

Both COX-1 and COX-2 are expressed in synovial tissues of patients with arthritis. COX-1 is localized at the synovial lining layer, and there is no difference in the level of expression in inflammatory versus noninflammatory arthritides (32). COX-2 is localized to the sublining layers, particularly the vascular endothelial cells, infiltrating mononuclear inflammatory cells, and fibroblast-like synoviocytes. Its expression is increased in inflammatory forms of arthritis $(32,33)$.

The role of PGs in inflammation and pain is both local and central within the nervous system. In peripheral tissues, PGs prolong proinflammatory actions of bradykinin, histamine, nitric oxide, and other mediators. Centrally, there is constitutive expression of COX-2 in the spinal cord, which is up-regulated during inflammation (34). Animal models of inflammation have been used to address the relative roles of COX-1 and COX-2. These data demonstrate that peripheral tissue PG production can be a function of both COX-1 and COX-2 in different types of models (35). Markedly increased COX-2 expression that paralleled increased PG production has been seen in animal models of inflammatory arthritis and in the rat carrageenin- or lipopolysaccharide-stimulated air pouch models. Pharmacologic compounds that specifically inhibit COX-2 reversed inflammation in both of these models $(36,37)$. In the air pouch models, a specific inhibitor of COX-1 had no effect on $\mathrm{PGE}_{2}$ production (35). However, in a dermal Arthus reaction model, a specific inhibitor of COX-1 decreased production of PGs while a specific inhibitor of COX-2 had no effect (35). 
Findings in the carrageenin-induced footpad inflammation model were somewhat more complex. Both COX-1- and COX-2-specific inhibition decreased $\mathrm{PGE}_{2}$ production in inflamed tissues. However, only the specific COX-2 inhibitor inhibited inflammation and hyperalgesia. The antiinflammatory and analgesic activity of specific COX-2 inhibition correlated with decreased cerebrospinal fluid PG levels (35). Further studies demonstrated that intrathecal administration of a specific COX-2 inhibitor could block the initiation of thermal hyperalgesia (38). These data suggest the possibility that some antiinflammatory, as well as the analgesic, effects of COX-2 inhibition may result from blocking of neurogenic inflammation. This possibility, however, runs counter to the observation that inhibition of tissue $\mathrm{PGE}_{2}$ using a monoclonal antibody blocks inflammation equally as well as NSAIDs (39). Nevertheless, COX-2 in the central nervous system seems to play an important role in the therapeutic efficacy of NSAIDs and specific COX-2 inhibitors.

Fever occurs in response to inflammation and induction of cytokines. PGs have long been known to mediate the fever. COX-2 expression is induced in the brain vasculature, with temporal correlation to the development of fever (40). Moreover, mice with targeted COX-2 gene disruption fail to develop fever in response to inflammatory stimuli (41).

COX-2 in tissue repair. Induction of COX-2 represents an early response to tissue injury caused by a number of stimuli in many different tissues, and is likely to play a physiologic role in tissue repair. Of clinical interest, COX-2 expression is increased in the GI tract, similar to other tissues, in response to injury (42-45). Patients with Helicobacter pylori-associated ulceration have increased COX-2 expression in gastric mucosa. After treatment of the infection, COX-2 levels are decreased (43). The significance of COX-2 for producing protective prostanoids in these settings relative to COX-1-mediated PG production is not clear, although it has been shown that specific inhibition of COX-2 delays healing of gastric mucosal erosions and ulcers in mice (46). Inhibition of COX-2, using either standard NSAIDs or a specific inhibitor, has also been shown to increase mucosal damage and mortality related to perforation in a rat model of colitis (42). These data indicate that although COX-1 seems to be responsible for cytoprotection of normal gastroduodenal mucosa $(37,47,48)$, further clinical evaluation is needed to determine what role COX-2 may play in the healing of damaged GI mucosa.

COX-2 expression is increased in endothelial cells and myocytes of infarcted myocardium. COX-2 staining is also seen in myocytes of myocardial fibrosis associated with dilating cardiomyopathy (49). There is an emerging concept that COX-2 induction in endothelial cells may represent an important compensatory mechanism to defend against vascular injury in general and may also be cardioprotective (50). The observation that some COX-2 knockout mice develop cardiac fibrosis supports this hypothesis (51). The fact that only COX-1 is expressed in platelets and is responsible for thromboxane $\mathrm{A}_{2}\left(\mathrm{TXA}_{2}\right)$ production during platelet activation, while endothelial cells have the capacity to express both COX-1 and COX-2, may have implications regarding vascular physiology in patients treated with specific COX-2 inhibitors.

The notion that induction of COX-2 is critical to normal tissue repair is supported by observations in patients with idiopathic pulmonary fibrosis (IPF). Cultured lung fibroblasts from patients with IPF fail to express COX-2 in response to stimulation with IL-1 (52). This observation, taken together with data demonstrating that PGs influence the balance between collagen deposition and matrix metalloproteinase production in fibroblasts (53), indicates that failure to induce COX-2 normally may contribute to the development of fibrosis in IPF.

COX-2 in malignancy and angiogenesis. There is very strong evidence suggesting that PGs play a role in the progression of colon cancer. Animal models of colon carcinogenesis, genetic and induced, indicate significant inhibition by NSAID treatment (2). There is a $40-50 \%$ decreased risk for colorectal cancer in persons who take aspirin or NSAIDs regularly, and NSAIDs cause regression of preexisting adenomas in patients with familial adenomatous polyposis (2). COX-2 expression is up-regulated in adenomas and carcinomas of the colon in animals and humans. Specific COX-2 inhibition, either by targeted knockout of the COX-2 gene or by pharmacologic means, has been shown to effectively modulate colon carcinogenesis $(2,54)$. Several mechanisms for this effect have been proposed. Overexpression of COX-2 in rat intestinal epithelial cells results in resistance to apoptosis and several other phenotypic changes that could lead to dysregulation of growth and normal cell death (55). In addition, it has been suggested that overexpression of COX-2 could promote production of angiogenic factors (56). A role for COX-1 in colon carcinogenesis has not been excluded, and there may be mechanisms other than inhibition of COX by which NSAIDs are cancer chemopreventative (2). 
COX-2 as a mediator of physiologic processes. Although COX-2 was originally described as mediating production of pathologic $\mathrm{PGs}$, it is clear that COX-2 also catalyzes formation of prostanoids that are important for physiologic functions (Figure 1). Although use of NSAIDs is known to prolong labor, the extent of COX-2 involvement in reproductive function was perhaps not fully appreciated until it was shown that COX-2 knockout mice had impaired fertility (57). It is now evident that COX-2 is rapidly and transiently induced by luteinizing hormone in preovulatory follicles and may be responsible for the precise timing of ovulation $(58,59)$. In addition, there is a focal increase of COX-2 expression at the site of blastocyst attachment in the uterus (60). COX-2 is highly expressed constitutively in the vas deferens of the adult male rat. Expression appears to be dependent on androgen since castration depletes COX-2 and androgen replacement after castration restores levels of COX-2 (61). It was recently reported that $\mathrm{COX}-2$ is expressed in the fetal lamb ductus arteriosus, predominantly in endothelial cells, while COX-1 is expressed in endothelium and smooth muscle. Both contributed to production of $\mathrm{PGE}_{2}$ by ductus tissue (62).

It has been known for many years that PGs are potent regulators of bone metabolism. Mechanical forces, hormones, cytokines, and growth factors increase production of prostanoids in skeletal tissues. It has recently been recognized that this is related, in large part, to transcriptional regulation of COX-2 (63), although COX-1 is also present in these tissues and the relative roles of the isoforms have yet to be fully elucidated (64). This is a potentially critical question if prostanoids produced by different isoforms regulate different aspects of bone remodeling. For example, mechanical loading significantly increases the rate of endocortical bone formation. Whereas indomethacin only partially inhibited bone formation in this model, a specific COX-2 inhibitor completely blocked bone formation (65).

In pancreatic islets, $\mathrm{COX}-2$ is the dominant isoform both under basal conditions and, as expected, after stimulation by IL-1 (66). PGs were previously shown to inhibit glucose-induced insulin secretion, but the implications of COX-2 expression in islet cells remain uncertain (66).

Prostanoids are involved in multiple physiologic processes in the lung, including regulation of pulmonary vascular tone, regulation of capillary endothelial and alveolar epithelial permeability, surfactant homeostasis, and control of bronchial mucous secretion and transport (67). COX-1 and COX-2 are expressed in different cells and tissues of the lung. COX-2 is expressed under basal conditions in macrophage- and mast cell-like cells in proximity to bronchial epithelium. Expression of COX-2 is also observed in smooth muscle cells of muscular arteries (67). The significance of distinct patterns of expression of the COX isoforms in different cells of the lung in regard to pulmonary physiology must be evaluated further.

COX-2 expression is regulated developmentally in the rat brain, with adult expression mostly in neurons of the limbic system and cortex (68). Up-regulation of COX-2 occurs in response to experimentally induced seizures as well as normal neuronal activity. COX-2 is hypothesized to play a role in development of Alzheimer's disease, although data are conflicting as to whether COX-2 is actually increased or decreased in the brain of patients with this disease (69-72).

The critical role of PGs in renal physiology is demonstrated by the fact that alterations in renal function develop in some patients treated with NSAIDs. Localization studies of the COX isoforms in rat kidney have demonstrated distinct expression of COX-1 and COX-2. COX-2 is expressed in the adult rat renal cortex in a restricted subpopulation of cells localized to the cortical thick ascending limb cells in the regions of the macula densa and in medullary interstitial cells (73). The macula densa is an important site of regulation of glomerular blood flow and renin release. When rats were subjected to sodium restriction, $\mathrm{COX}-2$ localized to the macula densa increased (73). It has been suggested that PGs produced via the COX-2 pathway may stimulate renin release. Further studies are needed to clarify whether COX-2 is similarly localized in the human kidney, but preliminary studies have indicated that COX-2 is present in the glomerular podocytes and the vasculature $(74,75)$.

Evidence that COX-2 plays a role in renal function in humans is provided by clinical trials demonstrating an excess of edema when high doses of specific COX-2 inhibitors are given (76). Additionally, in healthy elderly volunteers, specific COX-2 inhibitors decreased renal prostacyclin production and led to a significant transient decline in urinary sodium excretion $(77,78)$. Whereas the changes in sodium excretion were comparable between specific COX-2 inhibitors and nonspecific NSAIDs, only nonspecific NSAIDs reduced the glomerular filtration rate in subjects with normal renal function (78).

COX-2 plays a role in the development of the rodent kidney, as demonstrated by the finding of severe renal abnormalities in COX-2 knockout mice $(14,51)$. 
Localization studies show that COX-2 expression is subject to developmental control in the rat kidney, with peak expression in the second and third postnatal weeks and declining to adult levels by the third month (79).

PGs are regulators of platelet and endothelial cell function and, as such, modulate the hemostatic/ thrombotic balance. COX-2 appears to play a role in the production of endothelial $\mathrm{PGI}_{2}$. In vitro studies demonstrate that COX-2 expression is up-regulated in endothelial cells by laminar shear stress (80). Furthermore, specific COX-2 inhibitors decrease systemic $\mathrm{PGI}_{2}$ production in healthy volunteers $(77,78)$. Clinical implications of these biologic observations are currently unknown, and the possibilities are discussed below.

\section{Specific COX-2 inhibition in clinical practice}

Definition of specific COX-2 inhibition. Several levels of data are available to determine whether a compound is, in fact, a specific COX-2 inhibitor. First, the compound should exhibit specificity in vitro. In vitro specificity, however, is far from adequate and can only be suggestive of specificity because of the large number of variables in this type of assay (81). The most widely accepted ex vivo measure of COX-2 specificity is the whole blood assay. The assay is performed by measuring both COX-1 and COX-2 activity in a single sample. COX-1 activity is measured by determining thromboxane $\mathrm{B}_{2}$, the breakdown product of platelet $\mathrm{TBA}_{2}$, during whole blood clotting. COX-2 activity is measured by determining PG production from stimulated monocytes (12). Specific COX-2 inhibitors should not inhibit platelet aggregation over the entire range of doses and times in which PG production from stimulated monocytes is maximally inhibited (81). For the purpose of this discussion, celecoxib and rofecoxib will be considered specific COX-2 inhibitors $(47,82)$.

Implicit in the designation of a compound as a specific COX-2 inhibitor is the notion that there will be fewer clinically meaningful GI effects, i.e., ulcer with bleeding, perforation, or obstruction. As more is learned about the normal physiology of COX-2, the clinical definition of a specific inhibitor may change (Figure 2). Nevertheless, from a clinical standpoint, there are two key questions for evaluating the specific COX-2 inhibitors in comparison with other NSAIDs: Are they equally effective for arthritis and/or pain? Are there differences in the side effect profiles?

Efficacy of specific COX-2 inhibitors in arthritis and pain. Experience with both celecoxib and rofecoxib suggests that their efficacy is equal to that of nonselec-

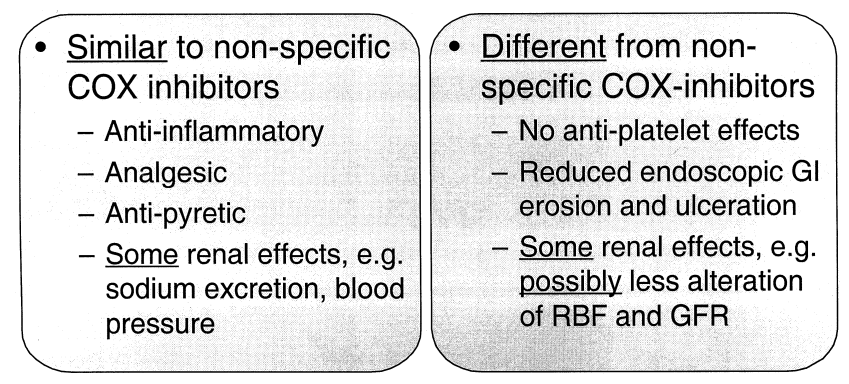

Figure 2. Clinical effects of cyclooxygenase-2 (COX-2) inhibitors. Specific COX-2 inhibitors share therapeutic effects and some side effects with nonspecific COX inhibitors. The primary differences between specific COX-2 inhibitors and nonspecific COX inhibitors are the lack of antiplatelet activity and reduction of gastroduodenal mucosal injury with specific COX-2 inhibitors. There may be distinct roles for the different $\mathrm{COX}$ isoforms in renal physiology. As the biology of the COX isoforms is clarified, clinical definitions of the specific $\mathrm{COX}-2$ inhibitors may change. $\mathrm{GI}=$ gastrointestinal; $\mathrm{RBF}=$ renal blood flow; GFR $=$ glomerular filtration rate.

tive NSAIDs. In the first 2-week trial of celecoxib in OA, celecoxib at doses of $100 \mathrm{mg}$ and $200 \mathrm{mg}$ twice daily was superior to placebo at weeks 1 and 2 as measured by visual analog scale for pain and by patient global assessment (47). In RA, celecoxib at $200 \mathrm{mg}$ and $400 \mathrm{mg}$ twice daily was superior to placebo at weeks 1,2 , and 4 for patient global assessment and number of tender/painful joints. Celecoxib at a dosage of $40 \mathrm{mg}$ twice daily was effective in OA at week 1, but was ineffective in RA (47). The frequency of withdrawals due to inefficacy in the RA trial was significantly lower for celecoxib at $200 \mathrm{mg}$ and $400 \mathrm{mg}$ twice daily (4\% and $6 \%$, respectively) than for placebo and celecoxib at $40 \mathrm{mg}$ twice daily (18\% and $17 \%$, respectively) (47).

The efficacy of rofecoxib $(50 \mathrm{mg}$ and $500 \mathrm{mg}$ ) was comparable with that of ibuprofen $(400 \mathrm{mg}$ ) and superior to that of placebo in a dental pain model of analgesic effect (82). Early studies in OA of the knee demonstrated efficacy of rofecoxib compared with placebo at daily dosages of $25 \mathrm{mg}$ and $125 \mathrm{mg}$ for 6 weeks ( $\mathrm{n}=72-74$ per group), with decreased pain and improved function evident by 1 week and sustained over the duration of the study (76). There were fewer withdrawals because of lack of efficacy in the rofecoxib groups, and there was no difference in the number of adverse events among groups (76). There was, however, an increased number of patients reporting lower extremity edema in the rofecoxib $125 \mathrm{mg}$ group $(6.8 \%$, compared with $0 \%$ in the placebo group).

In a 52-week trial of rofecoxib at $12.5 \mathrm{mg}$ or 25 $\mathrm{mg}$ twice daily compared with diclofenac at $75 \mathrm{mg}$ twice 
daily in patients with OA of the knee or hip ( $\mathrm{n}=$ 257-268 per group), rofecoxib was comparable with diclofenac for all efficacy outcome measures (83). Treatment responses were seen in all treatment groups at the first time point studied, and were sustained at a generally consistent level throughout the entire year of treatment (83). Response was observed in a variety of parameters, including stiffness, physical function, and study joint tenderness, and occurred in both OA of the knee and OA of the hip (83). There were no significant differences in the rates of discontinuation due to inefficacy.

GI effects of specific COX-2 inhibitors. Simon et al published the first results suggesting potential for improved GI safety with celecoxib (47). A short-term (61/2-day) study in healthy volunteers demonstrated marked reduction of endoscopically evident ulcers and erosions among patients treated with celecoxib compared with those receiving naproxen ( $\mathrm{n}=32$ per group). The incidence of ulcers $>3 \mathrm{~mm}$ in the naproxen group was $19 \%$, whereas there were no ulcers in the placebo or celecoxib groups. There was a $72 \%$ incidence of gastric erosion or ulcer in the naproxen group, compared with $9-13 \%$ in the placebo and celecoxib groups. In the published clinical experience for celecoxib in normal volunteers and patients with OA and RA, the incidences of nausea, dyspepsia, and abdominal pain were somewhat less than for a comparitor NSAID (naproxen). However, there were no differences in the rates of withdrawals from efficacy trials because of adverse events (47).

Two large endoscopic studies of 24 weeks' duration compared endoscopic outcomes of treatment with rofecoxib at a dosage of $25 \mathrm{mg}$ or $50 \mathrm{mg}$ per day, ibuprofen $800 \mathrm{mg} 3$ times daily, and placebo ( $\mathrm{n}=$ 340-373 per group [pooled data from both studies]). The studies were performed in OA patients $>50$ years of age. Patients with active erosive esophagitis or active upper GI ulceration were excluded, but patients with an earlier history of ulcer, perforation, or GI hemorrhage (9-13\%), gastroduodenal erosions (9-20\%), or H pylori infection $(52-57 \%)$ at baseline were eligible, and their numbers were comparable among groups. The frequency of endoscopic ulcers $\geq 3 \mathrm{~mm}$ was significantly lower in the rofecoxib groups compared with the ibuprofen group at 6,12 , and 24 weeks. At the 12 -week time point, the frequency of ulcers was $7.34 \%$ in the placebo group, $4.69 \%$ in the lower-dose rofecoxib group, $8.07 \%$ in the higher-dose rofecoxib group, and $28.47 \%$ in the ibuprofen group (48). Placebo treatment was not continued to 24 weeks, but the marked difference between rofecoxib and ibuprofen was maintained (ulcer frequency at 24 weeks $9.74 \%, 13.53 \%$, and $46.36 \%$ for rofecoxib $25 \mathrm{mg}$, rofecoxib $50 \mathrm{mg}$, and ibuprofen $800 \mathrm{mg}$, respectively). Earlier history of GI events and baseline erosions were associated with increased ulcer incidence in all groups, but $H$ pylori status was not. There was no evidence that rofecoxib additionally enhanced gastric injury in these subgroups (48).

GI symptom side effect profiles in a 52-week efficacy trial of rofecoxib $12.5 \mathrm{mg}$ or $25 \mathrm{mg}$ twice daily compared with diclofenac $150 \mathrm{mg}$ twice daily in OA were similar between groups ( $\mathrm{n}=257-268$ per group) (83). The incidence of nausea was $6.2 \%, 7.4 \%$, and $9.7 \%$ in the rofecoxib $12.5 \mathrm{mg}$, rofecoxib $25 \mathrm{mg}$, and diclofenac groups, respectively, and the incidence of drug-related combined GI adverse events was $18.1 \%, 20.6 \%$, and $19.8 \%$, respectively. The rate of discontinuation because of GI adverse events was similar between groups (83).

These early clinical trials demonstrate that endoscopic ulceration is significantly reduced with specific COX-2 inhibitors. However, too few patients have been studied to be able to definitively demonstrate a reduction in clinically significant GI events. The endoscopic data combined with lack of platelet effect give reason for optimism that the specific COX-2 inhibitors will have an improved GI safety profile compared with nonspecific NSAIDs (48). It may be that specific inhibition of COX-2 in the setting of an active or healing ulcer (both specifically excluded in the endoscopic trials) will be associated with risk of complications, although it seems unlikely that the risk with a specific COX-2 inhibitor will be equally as high as that with traditional NSAIDs. Nevertheless, based on the information that COX-2 is increased in ulcer margins, it is prudent to recommend that ulcers be treated prior to initiation of therapy with specific COX-2 inhibitors. It bears repeating that data do not demonstrate a significant reduction of non-ulcerrelated GI symptoms (nausea, dyspepsia, abdominal pain) with the specific COX-2 inhibitors.

Other clinical considerations. It is worth emphasizing that patients in need of cardiovascular or cerebrovascular protection should be treated with low-dose aspirin when specific COX-2 inhibitors or nonspecific NSAIDs are used (83). The incidence of cardiovascular thromboembolic events was not different between specific COX-2 inhibitors and nonspecific NSAIDs in the reported clinical trials (83), but inhibition of COX-1 has a clear role in antiplatelet activity of aspirin and nonspecific NSAIDs (1). It would also seem prudent to consider low-dose aspirin prophylaxis if a specific COX-2 inhibitor is used in patients with risk factors for 
thromboses, especially those with connective tissue diseases associated with vasculitis or vasculopathy, where expression of COX-2 may be increased. The addition of aspirin to a regimen of treatment with a specific COX-2 inhibitor will, of course, alter the overall risk for GI side effects and other bleeding complications $(84,85)$.

There is little information regarding clinical use of specific COX-2 inhibitors in other situations in which nonselective NSAIDs are not generally recommended, particularly among patients with intrinsic or functional renal insufficiency. High doses of rofecoxib $(125 \mathrm{mg}$ ) have been shown to be associated with an increased incidence of lower extremity edema, although at the dosages effective for OA $(12.5 \mathrm{mg})$, the frequency of this side effect is not different from that with nonselective NSAIDs $(76,83)$. In the large OA trials, there were no meaningful changes in blood pressure or serum creatinine levels in any group (83). However, data from normal volunteers suggest that specific COX-2 inhibitors will have renal effects, i.e., on sodium excretion (78). Until more data are available, patients with intrinsic or functional renal disease that would not be treated with an NSAID should not be viewed as candidates for therapy with a specific COX-2 inhibitor. Similarly, there is no information regarding use of these agents in patients with aspirin-induced asthma. Although these drugs could be useful in the pre- and postoperative period since they do not inhibit platelet function $(47,82)$, studies to demonstrate proper healing of wounds and bone have not yet been reported. It should be noted that celecoxib has a sulfonamide moiety, and caution should be used if a patient has a known allergy to sulfa drugs.

\section{Summary}

In summary, COX-2 is a highly regulated gene product that catalyzes the local production of PGs in pathologic and physiologic situations (Figure 1). It is clear that COX-2 is the isoform responsible for production of the PGs that mediate inflammation, pain, and fever. However, the role for COX-2 in normal physiology is still being defined. Specific COX-2 inhibitors represent a significant conceptual advance in therapy for patients with arthritis. Although there is no expectation of superior efficacy, clinical trials suggest that efficacy will be comparable with that of nonselective NSAIDs. Clinical trials demonstrate the potential for clinically meaningful reductions in the incidence of the most serious GI complications found with nonselective NSAIDs, i.e., ulcer, perforation, and GI bleeding. Over the next several years, treatment of large numbers of patients with specific COX-2 inhibitors will help to define the biology of COX-2. The magnitude of this advance in the therapy of rheumatic diseases is yet to be accurately determined, but the development of specific COX-2 inhibitors may afford significant new treatment options for many patients.

\section{REFERENCES}

1. Patrono C. Aspirin as an antiplatelet drug. N Engl J Med 1994;330:1287-94.

2. DuBois RN, Abramson SB, Crofford L, Gupta RA, Simon LS, van de Putte LBA, et al. Cyclooxygenase in biology and disease. FASEB J 1998;12:1063-73.

3. Vane JR. Inhibition of prostaglandin synthesis as a mechanism of action for aspirin-like drugs. Nature 1971;231:232-5.

4. Smith WL. Prostanoid biosynthesis and mechanisms of action. Am J Physiol 1992;263:F181-91.

5. Masferrer JL, Zweifel BS, Seibert K, Needleman P. Selective regulation of cellular cyclooxygenase by dexamethasone and endotoxin in mice. J Clin Invest 1990;86:1375-9.

6. Sano H, Hla T, Maier JAM, Crofford LJ, Case JP, Maciag T, et al. In vivo cyclooxygenase expression in synovial tissues of patients with rheumatoid arthritis and osteoarthritis and rats with adjuvant and streptococcal cell wall arthritis. J Clin Invest 1992;89:97-108.

7. Kujubu DA, Fletcher BS, Varnum BC, Lim RW, Herschman HR. TIS10, a phorbol ester tumor promoter-inducible mRNA from Swiss 3T3 cells, encodes a novel prostaglandin synthase/ cyclooxygenase homologue. J Biol Chem 1991;266:12866-72.

8. Xie W, Chipman JG, Robertson DL, Erikson RL, Simmons DL. Expression of a mitogen-responsive gene encoding prostaglandin synthase is regulated by mRNA splicing. Proc Natl Acad Sci U S A $1991 ; 88: 2692-6$.

9. Crofford LJ. COX-1 and COX-2 tissue expression: implications and predictions. J Rheumatol 1997;24 Suppl 49:15-9.

10. Wang LH, Hajibeigi A, Xu XM, Loosemitchell D, Wu KK. Characterization of the promoter of human prostaglandin $\mathrm{H}$ synthase-1 gene. Biochem Biophys Res Commun 1993;190:406-11.

11. Smith CJ, Morrow JD, Roberts LJ, Marnett LJ. Differentiation of monocytoid THP-1 cells with phorbol ester induces expression of prostaglandin endoperoxide synthase-1 (cox-1). Biochem Biophys Res Commun 1993;192:787-93.

12. Patrignani P, Panara MR, Greco A. Biochemical and pharmacological characterization of the cyclooxygenase activity of human blood prostaglandin endoperoxide synthases. J Pharmacol Exp Ther 1994;271:1705-12.

13. Langenbach R, Morham SG, Tiano HF, Loftin CD, Ghanayem BI, Chulada PC, et al. Prostaglandin synthase 1 gene disruption in mice reduces arachidonic acid-induced inflammation and indomethacin-induced gastric ulceration. Cell 1995;83:483-92.

14. Morham SG, Langenbach R, Loftin CD, Tiano HF, Vouloumanos $\mathrm{N}$, Jennette JC, et al. Prostaglandin synthase 2 gene disruption causes severe renal pathology in the mouse. Cell 1995;83:473-82.

15. Yamamoto K, Arakawa T, Ueda N, Yamamoto S. Transcriptional roles of nuclear factor $\mathrm{kB}$ and nuclear factor-interleukin-6 in the tumor necrosis factor-dependent induction of cyclooxygenase-2 in MC3T3-E1 cells. J Biol Chem 1995;270:31315-20.

16. Gou Q, Liu CH, Ben-Av P, Hla T. Dissociation of basal turnover and cytokine-induced transcript stabilization of the human cyclooxygenase- 2 mRNA by mutagenesis of the $3^{\prime}$-untranslated region. Biochem Biophys Res Commun 1998;242:508-12.

17. Ristimaki A, Narko K, Hla T. Down-regulation of cytokineinduced cyclo-oxygenase- 2 transcript isoforms by dexamethasone: 
evidence for post-transcriptional regulation. Biochem J 1996;318: 325-31.

18. Ristimaki A, Garfinkel S, Wessendorf J, Maciag $\mathrm{T}$, Hla $\mathrm{T}$. Induction of cyclooxygenase-2 by interleukin-1 alpha: evidence for post-transcriptional regulation. J Biol Chem 1994;269:11769-75.

19. Crofford LJ, Wilder RL, Ristimaki AP, Remmers EF, Epps HR, Hla T. Cyclooxygenase- 1 and -2 expression in rheumatoid synovial tissues: effects of interleukin-1 $\beta$, phorbol ester, and corticosteroids. J Clin Invest 1994;93:1095-101.

20. Crofford LJ, Tan B, McCarthy CJ, Hla T. Involvement of nuclear factor $\kappa \mathrm{B}$ in the regulation of cyclooxygenase- 2 expression by interleukin-1 in rheumatoid synoviocytes. Arthritis Rheum 1997; 40:226-36.

21. Schmedtje JF, Yan-Shan J, Liu W-L, DuBois RN, Runge MS. Hypoxia induces cyclooxygenase-2 via the NF-kB p65 transcription factor in human vascular endothelial cells. J Biol Chem 1997;272: 601-8.

22. Herschman HR, Reddy ST, Xie W. Function and regulation of prostaglandin synthase-2. Adv Exp Biol Med 1997;407:61-6.

23. DeWitt DL, Meade EA. Serum and glucocorticoid regulation of gene transcription and expression of the prostaglandin $\mathrm{H}$ synthase- 1 and prostaglandin $\mathrm{H}$ synthase-2 isozymes. Arch Biochem Biophys 1993;306:94-102.

24. DeWitt DL. Prostaglandin endoperoxide synthase: regulation of enzyme expression. Biochim Biophys Acta 1991;1083:121-34.

25. Morita I, Schindler M, Regier MK, Otto JC, Hori T, DeWitt DL, et al. Different intracellular locations for prostaglandin endoperoxide H synthase-1 and -2. J Biol Chem 1995;270:10902-8.

26. Spencer AG, Woods JW, Arakawa T, Singer II, Smith WL. Subcellular localization of prostaglandin endoperoxide $\mathrm{H}$ synthases- 1 and -2 by immunoelectron microscopy. J Biol Chem 1998;273:9886-93.

27. Murakami M, Nakatani Y, Atsumi G-I, Inoue K, Kudo I. Regulatory functions of phospholipase A2. Crit Rev Immunol 1997;17: 225-83.

28. Leslie CC. Properties and regulation of cytosolic phospholipase A2. J Biol Chem 1997;272:16709-12.

29. Kurumbail RA, Stevens AM, Gierse JK, McDonald JJ, Stegeman RA, Pak JY, et al. Structural basis for selective inhibition of cyclooxygenase- 2 by anti-inflammatory agents. Nature 1996;384: 644-8.

30. Reike CJ, Mulichak AM, Garavito RM, Smith WL. The role of arginine 120 of human prostaglandin endoperoxide $\mathrm{H}$ synthase- 2 in the interaction with fatty acid substrates and inhibitors. J Biol Chem 1999;274:17109-14.

31. Serhan CN. Lipoxins and novel aspirin-triggered 15-epi-lipoxins (ATL): a jungle of cell-cell interactions or a therapeutic opportunity? Prostaglandins 1997;53:107-37.

32. Siegle I, Klein T, Backman JT, Saal JG, Nüsing RM, Fritz P. Expression of cyclooxygenase 1 and cyclooxygenase 2 in human synovial tissue: differential elevation of cyclooxygenase 2 in inflammatory joint diseases. Arthritis Rheum 1998;41:122-9.

33. Crofford LJ. Expression and regulation of COX-2 in synovial tissues of arthritis patients. In: Vane J, Botting J, Botting R, editors. Improved non-steroid anti-inflammatory drugs: COX-2 enzyme inhibitors. London: Kluwer Academic Publishers and William Harvey Press; 1996. p. 133-43.

34. Beiche F, Scheuerer S, Brune K, Geisslinger G, Goppelt-Struebe M. Up-regulation of cyclooxygenase-2 mRNA in the rat spinal cord following peripheral inflammation. FEBS Lett 1996;390: 165-9.

35. Smith CJ, Zhang Y, Koboldt CM, Muhammed J, Zweifel BS, Shaffer A, et al. Pharmacological analysis of cyclooxygenase-1 in inflammation. Proc Natl Acad Sci U S A 1998;95:13313-8.

36. Anderson GD, Hauser SD, Bremer ME, McGarity KL, Isakson PC, Gregory SA. Selective inhibition of cyclooxygenase-2 reverses inflammation and expression of COX-2 and IL-6 in rat adjuvant arthritis. J Clin Invest 1996;97:2672-9.

37. Seibert K, Zhang Y, Leahy K, Hauser S, Masferrer J, Perkins W, et al. Pharmacological and biochemical demonstration of the role of cyclooxygenase 2 in inflammation and pain. Proc Natl Acad Sci U S A 1994;91:12013-7.

38. Dirig DM, Isakson PC, Yaksh TL. Effect of COX-1 and COX-2 inhibition on induction and maintenance of carrageenan-evoked thermal hyperalgesia. J Pharmacol Exp Ther 1998;285:1031-8.

39. Portanova JP, Zhang Y, Anderson GD, Hauser SD, Masferrer JL, Seibert K, et al. Selective neutralization of prostaglandin E2 blocks inflammation, hyperalgesia, and interleukin 6 production in vivo. J Exp Med 1996;184:883-91.

40. Cao C, Matsumura K, Yamagata K, Watanabe Y. Induction by lipopolysaccharide of cyclooxygenase-2 mRNA in rat brain: its possible role in the febrile response. Brain Res 1995;697:187-96.

41. Li S, Wang Y, Matsumura K, Ballou LR, Morhan SG, Blatteis $\mathrm{CM}$. The febrile response to lipopolysaccharide is blocked in cyclooxygenase-2(-/-), but not in cyclooxygenase-1(-/-) mice. Brain Res 1999;825:86-94.

42. Reuter BK, Asfaha S, Buret A, Sharkey KA, Wallace JL. Exacerbation of inflammation-associated colonic injury in rat through inhibition of cyclooxygenase-2. J Clin Invest 1996;98:2076-85.

43. McCarthy CJ, Crofford LJ, Greensom J, Scheiman JM. Cyclooxygenase- 2 expression in gastric antral mucosa before and after eradication of Helicobacter pylori infection. Am J Gastroenterol 1999;94:1218-23.

44. Eckmann L, Stenson WF, Savidge TC, Lowe DC, Barrett KE, Fierer $\mathrm{J}$, et al. Role of intestinal epithelial cells in the host secretory response to infection by invasive bacteria: bacterial entry induces epithelial prostaglandin $\mathrm{H}$ synthase-2 expression and prostaglandin E2 and F2 $\alpha$ production. J Clin Invest 1997;100:296309.

45. Singer I, Kawka DW, Schloemann S, Tessner T, Riehl T, Stenson WF. Cyclooxygenase 2 is induced in colonic epithelial cells in inflammatory bowel disease. Gastroenterology 1998;115:297-306.

46. Mizuno H, Sakamoto C, Matsuda K, Wada K, Uchida T, Noguchi $\mathrm{H}$, et al. Induction of cyclooxygenase 2 in gastric mucosal lesions and its inhibition by the specific antagonist delays healing in mice. Gastroenterology 1997;112:387-97.

47. Simon LS, Lanza FL, Lipsky PE, Hubbard RC, Talwalker S, Schwartz BD, et al. Preliminary study of the safety and efficacy of SC-58635, a novel cyclooxygenase 2 inhibitor: efficacy and safety in two placebo-controlled trials in osteoarthritis and rheumatoid arthritis, and studies of gastrointestinal and platelet effects. Arthritis Rheum 1998;41:1591-602.

48. Hawkey C, Laine L, Simon T, Beaulieu A, Maldonado-Cocco J, Acevedo E, et al. A comparison of the effect of rofecoxib (a COX-2 specific inhibitor), ibuprofen, or placebo on the gastroduodenal mucosa of osteoarthritics. Submitted for publication.

49. Wong SCY, Fukachi M, Melnyk P, Rodger I, Giaid A. Induction of cyclooxygenase- 2 and activation of nuclear factor- $\kappa \mathrm{B}$ in myocardium of patients with congestive heart failure. Circulation 1998;98:100-3

50. Wu KK. Cyclooxygenase-2 induction in congestive heart failure: friend or foe? Circulation 1998;98:95-6.

51. Dinchuk JE, Car BD, Focht RJ, Johnston J, Jaffee BD, Covington $\mathrm{MB}$, et al. Renal abnormalities and an altered inflammatory response in mice lacking cyclooxygenase II. Nature 1995;378: 406-9.

52. Wilborn J, Crofford LJ, Burdick MD, Kunkel SL, Strieter RM, Peters-Golden M. Cultured lung fibroblasts isolated from patients with idiopathic pulmonary fibrosis have a diminished capacity to synthesize prostaglandin E2 and to express cyclooxygenase-2. J Clin Invest 1995;95:1861-8.

53. Korn JH, Brinckerhoff CE, Edwards RL. Synthesis of PGE2, collagenase and tissue factor by fibroblast substrains: substrains 
are differentially activated for different metabolic products. Collagen Rel Res 1985;5:437-47.

54. Oshima M, Dinchuk JE, Kargman SL, Oshima H, Hancock B, Kwong E, et al. Suppression of intestinal polyposis in APCd716 knockout mice by inhibition of prostaglandin endoperoxide synthase-2 (COX-2). Cell 1996;87:803-9.

55. Tsujii M, DuBois RN. Alterations in cellular adhesion and apoptosis in epithelial cells overexpressing prostaglandin endoperoxide synthase 2. Cell 1995;83:493-501.

56. Tsujii M, Kawano S, Tsujii S, Sawaoka H, Hori M, DuBois RN. Cyclooxygenase regulated angiogenesis induced by colon cancer cells. Cell 1998;93:705-16.

57. Lim H, Paria BC, Das SK, Dinchuk JE, Langenback R, Trzaskos $\mathrm{JM}$, et al. Multiple female reproductive failures in cyclooxygenase 2-deficient mice. Cell 1997;91:197-208.

58. Sirois J, Dore M. The late induction of prostaglandin $G / H$ synthase in equine preovulatory follicles supports its role as a determinant of the ovulatory process. Endocrinology 1997;138: 4427-34.

59. Richards JS. Sounding the alarm: does induction of the prostaglandin endoperoxide synthase- 2 control the mammalian ovulatory clock? Endocrinology 1997;138:4047-8.

60. Chakraborty I, Das SK, Wang J, Dey SK. Developmental expression of the cyclo-oxygenase- 1 and cyclo-oxygenase- 2 genes in the peri-implantation mouse uterus and their differential regulation by the blastocyst and ovarian steroids. J Mol Endocrinol 1996;16:10722.

61. McKanna JA, Zhang M-Z, Wang J-L, Cheng H-F, Harris RC. Constitutive expression of cyclooxygenase-2 in rat vas deferens. Am J Physiol 1998;275:R227-33.

62. Clyman RI, Hardy P, Waleh N, Chen YQ, Mauray F, Fouron JC, et al. Cyclooxygenase-2 plays a significant role in regulating the tone of the fetal lamb ductus arteriosus. Am J Physiol 1999;273: R913-21.

63. Kawaguchi H, Pilbeam CC, Harrison JR, Raisz LG. The role of prostaglandins in the regulation of bone metabolism. Clin Orthop 1995;313:36-46.

64. Pilbeam CC, Fall PM, Alander CB, Raisz LG. Differential effects of nonsteroidal anti-inflammatory drugs on constitutive and inducible prostaglandin $\mathrm{G} / \mathrm{H}$ synthase in cultured bone cells. J Bone Miner Res 1997;12:1198-203.

65. Forwood MR. Inducible cyclo-oxygenase (COX-2) mediates the induction of bone formation by mechanical loading in vivo. $\mathrm{J}$ Bone Miner Res 1996;11:1688-93.

66. Sorli CH, Zhang H-J, Armstrong MB, Rajotte RV, Maclouf J, Robertson RP. Basal expression of cyclooxygenase-2 and nuclear factor-interleukin 6 are dominant and coordinately regulated by interleukin 1 in the pancreatic islet. Proc Natl Acad Sci U S A 1998;95:1788-93.

67. Ermert L, Ermert M, Goppelt-Struebe M, Walmrath D, Grimminger F, Steudel W, et al. Cyclooxygenase isoenzyme localization and mRNA expression in rat lungs. Am J Respir Cell Mol Biol 1998;18:479-88.

68. Yagamata K, Andreasson KI, Kaufmann WE, Barnes CA, Worley $\mathrm{PF}$. Expression of a mitogen-inducible cyclooxygenase in brain neurons: regulation by synaptic activity and glucocorticoids. Neuron 1993;11:371-86.

69. Chang JW, Coleman PD, O'Banion MK. Prostaglandin G/H synthase-2 (cyclooxygenase-2) mRNA expression is decreased in Alzheimer's disease. Neurobiol Aging 1996;17:801-8.

70. Tocco G, Freire-Moar J, Schreiber SS, Sakhi SH, Aisen PS, Pasinetti GM. Maturational regulation and regional induction of cyclooxygenase-2 in rat brain: implications for Alzheimer's disease. Exp Neurol 1997;144:339-49.

71. O'Banion MK, Chang JW, Kaplan MD, Yermakova A, Coleman PD. Glial and neuronal expression of cyclooxygenase-2: relevance to Alzheimer's disease. Adv Exp Med Biol 1997;433:177-80.

72. Lukiw WJ, Bazan NG. Cyclooxygenase 2 RNA message abundance, stability, and hypervariability in sporadic Alzheimer neocortex. J Neurosci Res 1997;50:937-45.

73. Harris RC, McKanna JA, Aiai Y, Jacobson HR, DuBois RN, Breyer MD. Cyclooxygenase-2 is associated with the macula densa of rat kidney and increases with salt restriction. J Clin Invest 1994;94:2504-10.

74. Komhoff M, Grone JJ, Klein T, Seyerth HW, Nusing RM. Localization of cyclooxygenase- 1 and cyclooxygenase- 2 in adult and fetal human kidney: implication for renal function. Am J Physiol 1997;272:F460-8.

75. Khan KNM, Verturini CM, Bunch RT, Brassard JA, Koki AT, Morris DL, et al. Interspecies differences in renal localization of cyclooxygenase isoforms: implication in nonsteroidal antiinflammatory drug-related nephrotoxicity. Toxicol Pathol 1998;27:61220.

76. Ehrich EW, Schnitzer TJ, McIlwain H, Levy R, Wolfe F, Weisman $\mathrm{M}$, et al. Effect of specific COX-2 inhibition in osteoarthritis of the knee: a 6-week double-blind, placebo-controlled, pilot study of rofecoxib. J Rheumatol 1999;26:2438-47.

77. McAdam BF, Catella-Lawson F, Mardini IA, Kapoor S, Lawson JA, FitzGerald GA. Systemic biosynthesis of prostacyclin by cyclooxygenase (COX)-2: the human pharmacology of a selective inhibitor of COX-2. Proc Natl Acad Sci U S A 1999;96:272-7.

78. Catella-Lawson F, McAdam B, Morrison BW, Kapoor S, Kujubu $\mathrm{D}$, Antes L, et al. Effects of specific inhibition of cyclooxygenase-2 on sodium balance, hemodynamics and vasoactive eicosanoids. J Pharmacol Exp Ther 1999;298:735-41.

79. Zhang M-Z, Whang J-L, Cheng H-F, Harris RC, McKanna JA. Cyclooxygenase-2 in rat nephron development. Am J Physiol 1997;273:F994-1002.

80. Topper JN, Cai J, Falb D, Gimbrone MA Jr. Identification of vascular endothelial genes differentially responsive to fluid mechanical stimuli: cyclooxygenase-2, manganese superoxide dismutase, and endothelial cell nitric oxide synthase are selectively up-regulated by steady laminar shear stress. Proc Natl Acad Sci U S A 1996;93:10417-22.

81. Lipsky PE, Abramson SB, Crofford L, DuBois RN, Simon L, van de Putte LBA. The classification of cyclooxygenase inhibitors. J Rheumatol 1998;25:2298-303.

82. Ehrich EW, Dallob A, De Lepeleire I, van Hecken A, Riendeau D, Yuan W, et al. Characterization of rofecoxib as a cyclooxygenase-2 isoform inhibitor and demonstration of analgesia in the dental pain model. Clin Pharmacol Ther 1999;65:336-47.

83. Cannon G, Caldwell J, Holt P, McLean B, Seidenberg B, Bolognese J, et al. Rofecoxib, a COX-2 specific inhibitor, has clinical efficacy comparable with diclofenac sodium: results of a one-year randomized clinical trial in patients with osteoarthritis of the knee and hip. Submitted for publication.

84. Bakowsky VS, Hanly JG. Complications of nonsteroidal antiinflammatory drug gastropathy and use of gastric cytoprotection: experience at a tertiary care health center. J Rheumatol 1999;26: 1557-63.

85. Kelly JP, Kaufman DW, Jurgelon JM, Sheehan J, Koff RS, Shapiro S. Risk of aspirin associated major upper gastrointestinal bleeding with enteric coated or buffered product. Lancet 1996;348: 1413-6. 